\title{
Perceptions of risk for stress fractures: A qualitative study of female runners with and without stress fracture histories.
}

\author{
Therese E Johnston \\ Thomas Jefferson University \\ Jeremy Close \\ Thomas Jefferson University \\ Phil Jamora \\ Thomas Jefferson University \\ Susan F Wainwright \\ Thomas Jefferson University
}

Follow this and additional works at: https://jdc.jefferson.edu/ptfp

Part of the Physical Therapy Commons

Let us know how access to this document benefits you

\section{Recommended Citation \\ Johnston, Therese E; Close, Jeremy; Jamora, Phil; and Wainwright, Susan F, "Perceptions of risk for stress fractures: A qualitative study of female runners with and without stress fracture histories." (2020). Department of Physical Therapy Faculty Papers. Paper 26. \\ https://jdc.jefferson.edu/ptfp/26}

This Article is brought to you for free and open access by the Jefferson Digital Commons. The Jefferson Digital Commons is a service of Thomas Jefferson University's Center for Teaching and Learning (CTL). The Commons is a showcase for Jefferson books and journals, peer-reviewed scholarly publications, unique historical collections from the University archives, and teaching tools. The Jefferson Digital Commons allows researchers and interested readers anywhere in the world to learn about and keep up to date with Jefferson scholarship. This article has been accepted for inclusion in Department of Physical Therapy Faculty Papers by an authorized administrator of the Jefferson Digital Commons. For more information, please contact: JeffersonDigitalCommons@jefferson.edu. 
Perceptions of Risk for Stress Fractures: A Qualitative Study of Female Runners with and without Stress Fracture Histories

Objectives: To gain insight into perceived factors related to bone health and stress fracture (SF) prevention for female runners and to understand their experiences within the medical community.

Design: Cohort qualitative study

Setting: University health system

Participants: Forty female runners, 20 who had SF histories and 20 age-and-running-distance matched women without SF.

Main Outcome Measures: Women participated in audiotaped qualitative semi-structured interviews. For women with a SF history, questions sought their perspectives on factors that they felt contributed to SF, experiences with the medical community, and changes made post SF. For women without a SF history, questions sought perspectives on factors felt important to perceived running-related bone health.

Results: Six themes emerged; 1) Previous/Recurrent Musculoskeletal Injuries, 2) Activity Patterns and Training Regimens, 3) Nutrition, 4) Prevention and Intervention, 5) Pain, and 6) Mindset. Within these themes, between group differences are characterized by differences in knowledge and/or application of knowledge for health and wellness. Compared to women without SF, women with SF histories increased training load more quickly, had poorer nutrition, performed less cross-training, and kept running despite pain.

Conclusions: More education is needed for female runners to decrease risks for SF.

Key Words: stress fracture; running; women 


\section{$\underline{\text { INTRODUCTION }}$}

More women are participating in running recreationally, competitively, and professionally. ${ }^{21} \mathrm{But}$ as women differ from men anatomically, physiologically, and psychologically, their risks for injury also differ. ${ }^{21}$ Thus, it is important to understand what factors impact risk. One injury that occurs in about $20 \%$ of runners is a stress fracture (SF),${ }^{34}$ which is sustained by more women than men. ${ }^{10,14} \mathrm{~A} \mathrm{SF}$ is defined as a non-traumatic incomplete fracture resulting from repetitive loading on normal bone or from normal loading on abnormal bone. ${ }^{8}$ Depending on the site of SF, return to full running can take up to several months, ${ }^{5,34}$ with recurrent SF being a concern. ${ }^{20}$ Many studies have examined the intrinsic and extrinsic risk factors related to SF. Intrinsic factors include bone structure and density, decreased fat, and nutrition, and hormones. ${ }^{8}$ Menstrual irregularities and energy deficiency are often present. ${ }^{25}$ These interrelated factors comprise the female athlete triad, a negative energy balance between nutritional intake and activity that can lead to menstrual issues and decreased bone mineral density, showing the inter-relationships of these factors. ${ }^{16}$ Both pre-menopausal and post-menopausal women are at risk. ${ }^{16,29}$ Extrinsic factors include training intensity, training surfaces, diet, and footwear. ${ }^{8}$

While many risk factors are known, more knowledge is still needed to best diagnose, treat, and prevent SF to allow women to experience the benefits of running. Critical to this knowledge are the thoughts and experiences of women themselves, and most studies do not seek these. One qualitative study that was conducted by Saragiotto et al. ${ }^{31}$ gathered beliefs and opinions of 95 recreational runners (30 female, $45 \%$ with prior running injuries) about risk factors for runningrelated injury. Common factors identified were wearing the wrong running shoes, excessive training, insufficient stretching or strengthening, and not listening to the body. Some information 
rated as important by runners, such as pre-run stretching and specific shoe types, was in conflict with published studies that did not find these to be important factors, ${ }^{17-19,28}$ showing a mismatch between runners' beliefs and research findings. This mismatch is important in designing effective prevention programs as cognitive and behavioral factors must be incorporated for success. ${ }^{31}$ One important finding in this study was that runners identified exceeding the body's limits as a factor for injury, which relates to self-perception of what these limitations are. In their study, Saragiotto et al. ${ }^{31}$ included men and women and all running injuries, which may impact the overall conclusions about perceptions. Thus, a focus on a specific injury for women is warranted. Due to the incidence of SF of up to $20 \%,{ }^{2}$ the time lost during recovery, and the importance of prevention and early detection, ${ }^{26}$ a study to gain a better understanding of the experiences for women with SF will better inform prevention and treatment programs.

To better understand risks for SF in female runners, the purpose of this qualitative study was to compare factors related to perceived bone health and SF prevention as reported by women who have and have not experienced running-related SF. A secondary purpose was to understand women's experiences within the medical community for diagnosis and treatment. The study by discusses the physiological results for this same group of women. The physiological data provide important information on body systems, but do not provide insight into possible factors that influenced these systems. The mixed-methods quantitative/qualitative research approach provides richer information to better understand the risk factors. 


\section{$\underline{\text { METHODS }}$}

Participants: Female recreational runners, age 18-65 years, with and without running-related SF histories were recruited as a convenience sample via posted flyers and social media. To control for differences in age and running ability, after each woman with a SF history was enrolled, a woman without a SF history was identified from women who responded who was age-matched within 5 years and running-distance-matched within 10 miles/week. ${ }^{2,35}$ All enrolled women signed an informed consent form approved by the governing Institutional Review Board.

Interview: All women participated in an audiotaped qualitative semi-structured interview with the first author (Appendix 1). Most interviews were conducted in-person. Due to scheduling challenges, 4 interviews were conducted and recorded using Google Voice using a desk top computer. For women with a SF history, goals were to obtain perspectives on factors that they felt contributed to the SF, their experiences with the medical community, and any changes made or planned to their approach to running. For women without a SF history, the goal was to obtain perspectives on factors felt important to perceived running-related bone health and SF prevention. A card sort technique was used to guide the interview. This card sort approach was individualized and allowed women to identify their own responses based on their experiences. ${ }^{23}$ Women were given 10 index cards or were asked to provide their own cards or paper to tear if using Google Voice. Women were then asked to write up to 10 factors (1 per card) that they felt contributed to the SF or health. They were not given any further details to avoid biasing their responses and they could write as few responses as they chose. They then rated these factors based on perceived relative importance, creating 3 stacks: most important, somewhat important, and least important factors. There was no minimum number required per stack. Starting with the 
most important factors, the women elaborated on the reasons that factor was important until each factor was discussed across all 3 piles. The first author asked questions to elicit more detail and a greater understanding of the participant's thoughts. Following the card sort, women with a SF history described their experiences with the medical community with SF diagnosis, treatment, and return to running. They then described any changes made or planned in their approach to running following SF. Finally, all women were asked if they had any other information to share. The interview audio file was uploaded onto a secure web-based data storage system. All interviews were transcribed verbatim by graduate research assistants. Each participant was assigned a unique identifying code.

Analysis: Data analysis was performed by the $3^{\text {rd }}$ and $4^{\text {th }}$ authors. Data were compared between groups and not within each pair as the matching was performed to obtain similar groups of participants across the diverse ages and mileage per week. Using a constant comparative method, ${ }^{24}$ categories and subcategories of data were created. Open coding was used to identify smallest units of data ${ }^{24,32}$ after each interview was read twice. Each line of interview data was read and a word or phrase was placed as an open code next to an identified word, phrase, or group of phrases that provided an answer to the research questions. A list of codes was identified and revised through an iterative process. ${ }^{6}$ Reliability of the open codes was determined by comparing the coding between the $3^{\text {rd }}$ and $4^{\text {th }}$ authors for $10 \%$ of the interview data. Percent agreement of $90.7 \%$ was achieved (Kappa statistic $=0.887)$. Once all open codes were identified, the $4^{\text {th }}$ author used axial coding to link data together, creating new connections and relationships between the open coded subcategories. ${ }^{6,24,32}$ Thus, the axial codes linked the open codes and 
represent a more diverse category that are reported as the themes. ${ }^{6}$ Data to support each theme are then reported as frequencies within groups to indicate differences between groups

\section{$\underline{\text { RESULTS }}$}

Forty-two women (35.0 \pm 7.4 , range 22-50 years) were enrolled. Two participants withdrew due to time constraints, and 40 participants (20 matched pairs) were interviewed. Women in the SF and non-SF groups were ages $35.1 \pm 7.2$ and $34.3 \pm 7.7$ years, respectively. Women had at least a bachelor's degree and were mainly white. Three women in the non-SF group were Asian and one woman in each group was Hispanic. Self-reported running information is provided in Table 1. Fracture sites included tibia $(\mathrm{n}=15)$, metatarsal $(\mathrm{n}=8)$, femur $(\mathrm{n}=5)$, cuneiform $(\mathrm{n}=1)$, and sesamoid $(\mathrm{n}=1)$ with 6 participants reporting having had $2 \mathrm{SFs}$, and 2 participants reporting 3 SFs. Women with SF histories were $2.2 \pm 2.6$ years post the most recent SF. Further information about the participants can be found in .15

TABLE 1. Running status

\begin{tabular}{llcc}
\hline Item & Choices & $\begin{array}{c}\text { Stress } \\
\text { Fracture (n) }\end{array}$ & $\begin{array}{c}\text { Non- } \\
\text { Fracture (n) }\end{array}$ \\
\hline Days/week & 2 & 0 & 1 \\
& 3 & 11 & 7 \\
& 4 & 4 & 4 \\
& 5 & 2 & 5 \\
& 6 & 2 & 1 \\
& 7 & 1 & 2 \\
Miles/week & $0-10$ & 1 & 1 \\
& $11-20$ & 6 & 9 \\
& $21-30$ & 6 & 6 \\
& $31-40$ & 4 & 2 \\
& $41-50$ & 1 & 1 \\
& $>50$ & 2 & 1 \\
& & & \\
& $<6$ & 1 & 0
\end{tabular}




\begin{tabular}{llll} 
Pace & $6-7$ & 0 & 1 \\
(minutes/mile) & $7-8$ & 6 & 2 \\
& $8-9$ & 2 & 6 \\
& $9-10$ & 7 & 4 \\
& $10-11$ & 4 & 5 \\
& $>11$ & 0 & 2 \\
\hline
\end{tabular}

Data collection of matched pairs between these two groups allowed across-group analysis. A number of themes emerged from the qualitative data: 1) Previous/Recurrent Musculoskeletal Injuries, 2) Activity Patterns and Training Regimens, 3) Nutrition, 4) Prevention and Intervention, 5) Pain, and 6) Mindset. Within these themes, the across group differences are characterized by differences in knowledge and/or application of knowledge. Figure 1 provides a schematic of these themes with examples for each as they relate to SF.

\section{Previous / Recurrent Musculoskeletal Injuries:}

Women in both groups identified having had musculoskeletal injuries that were often recurrent and ongoing, suggesting that injuries are common for female runners. Participants in both groups identified musculoskeletal concerns of shin splints (4), iliotibial band issues/hip pain (4), muscle strain/tear (4), "plantar issues"/plantar fasciitis (3), ankle sprain (2), tendonitis (2), tendinopathy (1), nerve entrapment (1), and mid-patellar chondrosis (1). These injuries had varying impact on continued running. All participants in the SF group and 50\% in the non-SF group relied on the expertise and opinion of a variety of consultants as they strove to maximize health and continue or resume training. Consultants included running coaches, physicians (sports medicine, orthopedist), nutritionists, physical therapists, chiropractors, podiatrists, and athletic trainers. 


\section{$\underline{\text { Activity Patterns and Training Regimens }}$}

Participants in the SF group $(n=11)$ talked about running a higher number of miles/week as compared to the non-SF group ( $n=1$, participant NSF\#14). The frequency and numbers of miles were perceived to be a contributing factor to developing SF:

"So going from... 30 miles a week and doing almost 50 to 60 miles per week and it's a quick buildup so that was probably the most contributing factor to getting a stress fracture." (SF\#14)

One participant without SF, who discussed the impact of training on perceived bone health, reported running 55-70 miles/week. But she recognized the importance of grading training:

"What some people do is, oh I ran 5 miles, let's see if I can do 10. And they try to do too much too quick and it kind of shocks their body and they get hurt." (NSF\#14)

When describing the approach to training post SF, women identified using broad approaches ranging from protocol driven regimens ("the Ohio State return to run after SF protocol") to random training schedules that resulted in re-injury for some participants:.

"I was running faster than I think I should have, especially on the long runs. I think that was probably one of the, well I think they all contribute (to re-injury). I think the speed was more of an issue than the distance." (SF\#10)

Those in the non-SF group described a more conservative approach to training:

"I have learned from experience and reading, that when you are going to increase your training or mileage, or whatever you are going to increase, you really have to be gradual about it if you want to avoid any type of injury; bone or otherwise. So the rule I have read and tried to follow is not more than 10\% increase in any one factor per week." (NSF\#2)

Both groups referenced benefits of running on softer surfaces, and reported running on a variety of surfaces inclusive of turf/grass, asphalt, trails, and treadmill ( $\mathrm{n}=7$ SF group, $\mathrm{n}=5$ NSF group). The SF group attributed changes in patterns as possibly contributing to occurrence of fractures. These patterns could be related to weather, schedules, or other life factors: 
"It was October and into November/December and I went from running outside, running on trails, running on soft surfaces to running just on a treadmill." (SF\#6)

Fatigue related to overtraining was identified as another contributing factor by approximately one-third of the SF participants as compared to none of the non-SF participants as exemplified by this quote:

"I was overtraining on all of that. I really think that led up to my stress fracture. "(SF\#11)

\section{$\underline{\text { Nutrition }}$}

Participants in both groups discussed their knowledge and approach to diet and use of supplements. Approximately one-third in the non-SF group identified adherence to good diet principles as being important. Their comments are characterized by statements such as below:

"(I) eat foods high in calcium, like dark leafy greens, other things, cheese, yogurt. The latter part is a little bit difficult because I am lactose intolerant. But there are work arounds. " (NSF\#4)

Conversely, 2 participants in the SF group who identified knowledge of good diet principles indicated that they did not consistently adhere to best practice as exemplified by this statement:

"I probably ate some chicken once in a while, a lot of pasta, cereal, maybe a little bit of yogurt. But nothing like 100\% nutrition based, I'm sure." (SF\#4)

No one in the SF group indicated routine use of good diet principles. Approximately two-thirds of the participants in the SF group identified nutritional deficiencies. Specifically, they described nutritional deficiencies in calcium (4), iron (4), insufficient caloric intake (4), protein (3), Vitamin D (3), fruits and vegetables (3), and dairy (3). The following quote illustrates these nutritional deficits:

“... not eating enough. I think it means for me it is a combination of the types of foods I was eating versus just not eating enough calories in general. I just was unaware that I wasn't paying as close attention to the nutrients I was putting in my body... calcium, vitamin D, fruits and vegetables. I think that definitely contributed." (SF\#3) 
While participants in both groups described examples of poor decisions with diet, those in the SF group did so three times as often as the non-SF group. Use of nutritional supplements was reported inconsistently across both groups. Approximately one third of the participants in the SF group and half in non-SF group identified using some form of daily nutritional supplement.

\section{$\underline{\text { Prevention and Intervention }}$}

Participants in both groups pursued a variety of options (physical therapy, self-directed exercise, footwear, and orthotics) to achieve their best possible health status that included rest. Participants in both groups ( $n=15$ SF group, $n=10$ NSF group) described the benefits of cross training to fitness and health. Despite this knowledge, not all participants applied this knowledge to training. All but one participant in the SF group described limited attention or focus on cross training as contributing to overall perceived bone health:

"Thinking of the plan that we had, it was supposed to have cross training in there, but it was really hard to fit that all in when I was supposed to be running so I just didn't do it." (SF\#13)

Participants in the non-SF group were more likely to describe ongoing engagement in cross training activities, including weight lifting, swimming, yoga, or Pilates.

Approximately one-third of those in the SF group talked about their time spent immobilized and/or unweighted following fracture. Further, $50 \%$ of those in the SF group described times in which they took time off from training to heal injuries related or unrelated to a primary SF. These decisions may be medically directed or self-imposed based on symptoms:

"I got the stress fracture in August, started running again in December, and then started increasing and felt it again in January or February. So then I stopped running again." (SF\#9) 
In comparison, none of the non-SF group sustained injury that necessitated medically prescribed rest. Only one participant in this group identified that they imposed their own rest on training.

$\underline{\text { Pain }}$

All participants in the SF group described pain being a limiting factor to training before or after the SF, and approximately half of the participants in this group provided examples of limitations on functional activities:

"When it happened at the all-city 20 miler, when I got home, I couldn't get out of the car. I couldn't actually move my leg to get out of the car, it was so painful. I just figured, what did I do." (SF\#13)

Conversely, approximately one-third of participants in the non-SF group mentioned pain.

Another difference between the two groups is how they responded to pain. Those in the non-SF group used pain as a warning sign:

“But I also quit before it gets bad. If I start to feel it, I won't push through it." (NSF\#8)

Those in the SF group were more likely to continue to run in the presence of pain:

"So, each time when my longer run got to like 8-10 miles, is when I felt the pain. At first I didn't know what it was so I kept running through it. And then, it was like bringing me to tears when I was running, and I could tell it wasn't muscle." (SF\#9)

\section{$\underline{\text { Mindset }}$}

One consistent finding across both groups was an awareness of body. Approximately half the participants in each group described how they used cues from their bodies, typically pain, to make decisions about activity level. Those in the non-SF group described using pain as a warning sign to modify the approach to training:

"... paying attention to those warning signs if something doesn't feel right like maybe I shouldn't wear these again.., or maybe I should wear them for a different type of workout, as 
opposed to wearing them for a speed workout or a long run. I think being really in tuned with your body or I guess your body's response to what you are wearing is important and paying attention to the signs." (NSF\#3)

The participants in the SF group adopted similar thought processes, but only upon serious injury. Fear was mentioned as a factor:

"... And so I'm still having some discomfort, nothing like it was. So that's why I went back to her, just like what's okay, what's not because now I'm really gun-shy... I would like to try to do another half, because you learn so much the first time you do that: mentally, physically, everything." (SF\#1)

One additional factor identified by half of the participants of those in the SF group and one fourth in the non-SF group was the importance of collegiality with an identified running community. This community had a positive effect, as exemplified by a participant in the SF group:

"Yeah it's this amazing group of people, it doesn't matter what your background is, your body shape or size, when you run, you have this instant bond." (SF\#5)

Community became a negative factor when it may not have been a good match as detailed by a participant in the SF group:

"And I was training for a marathon and was probably running too much, too many back to back days, not allowing my body any time to rest. Also trying to keep up with other people when I probably can't because I'm a lot older than them." (SF\#13)

\section{Experience with the Medical Community}

Participants with SF were also asked to comment on experiences with the medical community post SF. They expressed differing opinions in obtaining a diagnosis and with advice received on return to running. Many participants felt that they were not taken seriously when seeking initial diagnosis. Those experiencing their second or greater SF reported greater success in navigating the medical community. One participant who waited over a month for her SF diagnosis saw several different providers and reported this experience: 
"So I saw a sports med guy, who was kind of baffled. He was the one who was like 'Well, you can hop on one foot, you are probably fine'... That would be the one thing that was difficult to understand. Everyone was saying, "it HAS to look like this " and it didn't." (SF\#6)

Following SF healing, there was a wide variety of guidance given inclusive of details for resuming training, referrals to other health professionals such as a PT, nutritionist, or endocrinologist or advice to get a coach. Others were given no advice. One participant reported receiving the following advice:

"So he told me, 'biking is better than running for you.' He said to look into swimming. I didn't have access to a pool at the time. Then he did the whole... after 8 weeks start with $10 \%$ of running what you used to, etc." (SF\#9)

Other participants were given no advice as illustrated by this participant's comments:

"No one really pointed me in the right direction. They were just like take some time off...." (SF\#14)

Several participants reported the importance of finding a health professional with a running background. One participant reported a positive experience with a physician who was a runner:

"But this doctor, ... I find that when I see doctors that are runners, it is a lot easier for me. He's a marathon runner too." (SF\#15)

Assertiveness was also mentioned by participants when seeking care and guidance. One participant identified her success by being assertive:

"I went to an urgent care to get an X-ray on a weekend and then had an appointment with my primary care physician the following Monday and I told her that I wasn't leaving without an MRI script and a script for PT." (SF\#13)

Another participant expressed concern that she wasn't informed or assertive enough to get answers:

"Maybe it was just me at that point, I didn't know too much, what questions to ask, I was just assuming that they know what they are doing. I just didn't want to be in a boot again." (SF\#11) 


\section{Changes made following SF}

Women reported making various changes following the SF. The 5 most common changes reported were starting or increasing the amount of strengthening exercises (11), focusing more on proper nutrition (7), starting to take supplements such as calcium and vitamin D (7), adding cross training such as cycling or swimming (6), and altering running form (5). Other factors mentioned less commonly included running fewer days/week, increasing pace and miles more slowly, changing running surfaces, adding stretching, running fewer miles, stopping when pain occurred, changing running shoes and type of shoes worn daily, resting more, and getting sports massages. The median number of changes reported by the women was 3 (range 1-9).

\section{$\underline{\text { DISCUSSION }}$}

This study's purpose was to compare factors related to perceived bone health and SF prevention as reported by women who have and have not experienced running-related SF. Common themes were identified across women in both groups, some of which are reported in the literature. Almost all women in both groups reported some type of previous running related injury, but what differed between those with and without SF was in their approach to running related health and response to injury or pain. Thus, there are implications for both prevention and treatment of SF in female runners.

\section{$\underline{\text { Previous/Recurrent Musculoskeletal Injuries }}$}

Women in both groups reported having running related injuries during the interviews, which is concerning. Using a survey design, Fokkema et al. ${ }^{12}$ reported that $79.3 \%$ of their male and female respondents has sustained some type of running related injury. While not specific to SF, 
their findings along with the findings of this study stress the importance of prevention and education to decrease injury risk.

\section{Activity Patterns and Training Regimens}

Women with SF histories were more likely to increase mileage too quickly, experience fatigue and report overtraining, which are supported in the literature. Damsted et al. ${ }^{7}$ found that runners injured while training for a half marathon did so within the first 21 days, after increasing their weekly mileage by $20-60 \%$. Those without injury increased by less than $20 \%$. So running too much too soon was a concern for injury. ${ }^{7}$ Other studies have supported this finding, Saragiotto et al., ${ }^{31}$ reported that exceeding the body's limits was a self-identified factor for injury in recreational runners, Timpka et al. ${ }^{36}$ found that load on a body in need of rest was a concern, and Winter et al. ${ }^{38}$ reported that running kinetics changed negatively with fatigue. While not explored in this study, other studies provide insight into the psychological aspect that may be important in regard to overtraining. Ekenman et al. ${ }^{9}$ reported that injured high-school runners were more likely to have type A personalities and exercise dependency. While they studied high school runners, the presence of motivation, ambitiousness, and competitiveness at any age may lead to overtraining and thus injury. In a study with adult runners, Nezlek et al. ${ }^{27}$ reported that sense of accomplishment with running is influenced more by distance/day as compared to days/week, and Chalabaev et al. ${ }^{4}$ reported that runners perceived less risk for injury as their motivation to complete a marathon increased. Therefore, psychological factors need to be considered when treating runners. 


\section{$\underline{\text { Nutrition }}$}

In this study, many women with SF histories were less likely to follow a good nutritional plan.

Glabska et al. ${ }^{13}$ reported that 15-25 year-old female mid/long-distance runners did not reliably assess nutritional plan quality. The women with SF histories in our study were older than the women in Glabska et al. ${ }^{13}$ and reported an awareness of nutritional needs. But they were less likely to follow a good nutritional plan than women without SF. Therefore, education may be needed for both proper nutrition for running and on how to incorporate a good nutritional plan into busy daily lives.

\section{$\underline{\text { Prevention and Intervention }}$}

While women with SF reported knowing that cross training was important, they frequently stated that they were doing none or not as much as they should. Lack of time and fatigue were common reasons, which may relate to overtraining with running. Studies have shown the importance of cross training, which support the knowledge that the women reported having. Muscle strength and endurance are factors that can modify load applied to bone,${ }^{37}$ and bone stress injuries are related to muscle cross sectional area and strength. ${ }^{1}$ Blagrove et al. ${ }^{3}$ reported that strength training 2-3 times per week can provide benefits to middle and long distance runners, while Taunton et al. ${ }^{33}$ reported that swimming and cycling can replace some running training sessions to decrease overall forces. Women in this study recognized the importance of cross training but did not always complete it to the level they felt was important. Education on how to balance running and cross training along with the demands of everyday life is needed. 


\section{$\underline{\text { Pain }}$}

Women with SF histories were more likely to push through pain with training. In a study with elite youth runners, Timpka et al. ${ }^{36}$ found that self-perception can be an issue with runners misinterpreting pain as a temporary nuisance rather than a possible pathologic process. This misinterpretation of pain may have been a factor for the women with SF in this study. As stated earlier, motivation ${ }^{4}$ and personality ${ }^{9}$ may be factors related to pushing through pain. Therefore, women need more education on interpreting pain and determining when to stop a run, add more rest, and/or seek medical attention. A related mindset issue in this study was fear of re-injury. In a study of athletes post ACL reconstruction, half of participants who did not return to prior sport reported fear of re-injury and kinesiophobia as factors along with pain. ${ }^{11}$ Education may thus also be needed on interpreting and responding to pain when returning to sport.

\section{$\underline{\text { Mindset }}$}

Interestingly in this study, the social aspect of running was reported as both positive and negative. The instant bond of belonging to a group was a benefit, but the peer environment could cause women to push too hard. There is a large social impact of running with unity and participation leading to strong emotions. ${ }^{22}$ Mental well-being is an important aspect of group running, ${ }^{22}$ but women need to realize individual needs and respond appropriately to minimize injury risk. The women in this study who reported these social aspects benefitted from the sense of belonging. But it was also important to find the right group to avoid feeling peer pressure to push too far beyond current running ability 


\section{Experiences with the Healthcare Community}

For women with SF histories, experiences within the heath care community were varied. Being evaluated by a healthcare provider who was a runner or understood runners was seen as important. Many women reported having difficulty getting the SF diagnosis and with communicating the importance of the injury, indicating the need to be more assertive. They often felt lost as to what to do next as they navigated the healthcare system. Russell et al. ${ }^{30}$ studied what injured athletes wanted from a health care professional and found that they desired education about the injury, rehabilitation, and return to play. They also wanted time and communication with the provider and a positive and supportive environment. Thus, healthcare providers should strive to educate female runners about the injury and return to running as well as how to best advocate for themselves when an injury occurs.

$\underline{\text { Recommendations for Prevention and Treatment: The results of this study have implications for }}$ both prevention and treatment as women with SF reported running more, overtraining, and poorer nutrition and were less likely respond to pain. Based on what women reported, they need guidance on how to progress running safely. Recommendations in the literature for prevention of SF suggest that women should increase mileage, pace, or days running by less than $20 \%$ per week. $^{7}$ Along with a plan for appropriate increases in running, a plan for cross training 2-3 times per week ${ }^{3}$ should be incorporated that takes into account the amount of running for the woman's running goals as well as other life demands. Signs of fatigue need to be discussed as well as how to adapt the plan if fatigue becomes a concern. Psychological aspects should be explored that may lead to overtraining and misinterpretation of pain that could indicate a more significant injury. Nutritional needs should also be considered as some woman reported knowing their 
habits were poor. When examining all of these areas together, there is a lot to manage for these runners. A plan that considers all needs as a whole may lead to better success. Future research should provide a comprehensive education plan and assess its impact on decreasing running related injury, including SF.

The women who had a SF were able to return to running and made many important changes to their running plan. ${ }^{15}$ Due to the qualitative design of this study, the results captured what women reported during an interview and not based on selecting items from a list that may have led them to specific answers. Despite this, women reported changing factors that were often reported as important by the women without SF. This finding stresses the importance of educating female runners on the importance of these factors before a SF occurs as well as during the rehabilitation process following SF. Importantly, women should be educated on how to incorporate these changes into their already busy lives.

Study limitations: The sample of participants was one of convenience and thus may not represent the population of female runners as a whole. Participants were highly educated and predominantly white. Due to the varying lengths of time since SF occurrence, recall bias is possible. Despite this possible bias, women were very passionate about their responses and often described their experiences in great detail. Another potential source of bias is the influence of health professionals and others encountered since the SF occurred, who may have altered perceptions. However, these encounters are part of the experience, whether positive or negative, and the resulting perceptions are important to capture for health professionals to understand their influence on female runners. 


\section{Reference List}

(1) Beck TJ, Ruff CB, Shaffer RA, Betsinger K, Trone DW, Brodine SK. Stress fracture in military recruits: gender differences in muscle and bone susceptibility factors. Bone 2000 September;27(3):437-444.

(2) Bennell KL, Malcolm SA, Brukner PD et al. A 12-month prospective study of the relationship between stress fractures and bone turnover in athletes. Calcif Tissue Int 1998 July;63(1):80-85.

(3) Blagrove RC, Howatson G, Hayes PR. Effects of Strength Training on the Physiological Determinants of Middle- and Long-Distance Running Performance: A Systematic Review. Sports Med 2018 May;48(5):1117-1149.

(4) Chalabaev A, Radel R, Ben M, I, Massiera B, Deroche T, d'Arripe-Longueville F. Is motivation for marathon a protective factor or a risk factor of injury? Scand J Med Sci Sports 2017 December;27(12):2040-2047.

(5) Chen YT, Tenforde AS, Fredericson M. Update on stress fractures in female athletes: epidemiology, treatment, and prevention. Curr Rev Musculoskelet Med 2013 June;6(2):173-181.

(6) Colorafi KJ, Evans B. Qualitative Descriptive Methods in Health Science Research. HERD 2016 July;9(4):16-25.

(7) Damsted C, Parner ET, Sorensen H, Malisoux L, Hulme A, Nielsen RO. The Association Between Changes in Weekly Running Distance and Running-Related Injury: Preparing for a Half Marathon. J Orthop Sports Phys Ther 2019 April;49(4):230-238.

(8) Denay KL. Stress Fractures. Curr Sports Med Rep 2017 January;16(1):7-8. 
(9) Ekenman I, Hassmen P, Koivula N, Rolf C, Fellander-Tsai L. Stress fractures of the tibia: can personality traits help us detect the injury-prone athlete? Scand J Med Sci Sports 2001 April;11(2):87-95.

(10) Fields KB. Running injuries - changing trends and demographics. Curr Sports Med Rep 2011 September;10(5):299-303.

(11) Flanigan DC, Everhart JS, Pedroza A, Smith T, Kaeding CC. Fear of reinjury (kinesiophobia) and persistent knee symptoms are common factors for lack of return to sport after anterior cruciate ligament reconstruction. Arthroscopy 2013 August;29(8):1322-1329.

(12) Fokkema T, de Vos RJ, Bierma-Zeinstra SMA, van MM. Opinions, Barriers, and Facilitators of Injury Prevention in Recreational Runners. J Orthop Sports Phys Ther 2019 October;49(10):736-742.

(13) Glabska D, Jusinska M. Analysis of the choice of food products and the energy value of diets of female middle- and long-distance runners depending on the self-assessment of their nutritional habits. Rocz Panstw Zakl Hig 2018;69(2):155-163.

(14) Goldring AE, Ashok AP, Casey EK, Mulcahey MK. Key components and potential benefits of a comprehensive approach to women's musculoskeletal health. Phys Sportsmed 2016 November;44(4):417-424. Physiological Factors of Female Runners with and without Stress Fracture Histories: A Pilot Study. Sports Health. In press 2020.

(16) Joy EA, Campbell D. Stress fractures in the female athlete. Curr Sports Med Rep 2005 December;4(6):323-328. 
(17) Knapik JJ, Brosch LC, Venuto M et al. Effect on injuries of assigning shoes based on foot shape in air force basic training. Am J Prev Med 2010 January;38(1 Suppl):S197S211.

(18) Knapik JJ, Trone DW, Swedler DI et al. Injury reduction effectiveness of assigning running shoes based on plantar shape in Marine Corps basic training. Am J Sports Med 2010 September;38(9):1759-1767.

(19) Knapik JJ, Swedler DI, Grier TL et al. Injury reduction effectiveness of selecting running shoes based on plantar shape. J Strength Cond Res 2009 May;23(3):685-697.

(20) Korpelainen R, Orava S, Karpakka J, Siira P, Hulkko A. Risk factors for recurrent stress fractures in athletes. Am J Sports Med 2001 May;29(3):304-310.

(21) Lynch SL, Hoch AZ. The female runner: gender specifics. Clin Sports Med 2010 July;29(3):477-498.

(22) Malchrowicz-Mosko E, Poczta J. Running as a Form of Therapy Socio-Psychological Functions of Mass Running Events for Men and Women. Int J Environ Res Public Health 2018 October $16 ; 15(10)$.

(23) Mammen JR, Norton SA, Rhee H, Butz AM. New approaches to qualitative interviewing: Development of a card sort technique to understand subjective patterns of symptoms and responses. Int J Nurs Stud 2016 June;58:90-96.

(24) Merriam SB. Qualitative Research and Case Study Application in Education. San Francisco, CA: Jossey-Bass; 1998.

(25) Micklesfield LK, Hugo J, Johnson C, Noakes TD, Lambert EV. Factors associated with menstrual dysfunction and self-reported bone stress injuries in female runners in the 
ultra- and half-marathons of the Two Oceans. Br J Sports Med 2007 October;41(10):679683.

(26) Nattiv A, Loucks AB, Manore MM, Sanborn CF, Sundgot-Borgen J, Warren MP. American College of Sports Medicine position stand. The female athlete triad. Med Sci Sports Exerc 2007 October;39(10):1867-1882.

(27) Nezlek JB, Cypryanska M, Cypryanski P et al. Within-Person Relationships Between Recreational Running and Psychological Well-Being. J Sport Exerc Psychol 2018 June $1 ; 40(3): 146-152$.

(28) Nielsen RO, Buist I, Parner ET et al. Foot pronation is not associated with increased injury risk in novice runners wearing a neutral shoe: a 1-year prospective cohort study. $\mathrm{Br}$ J Sports Med 2014 March;48(6):440-447.

(29) Pegrum J, Crisp T, Padhiar N, Flynn J. The pathophysiology, diagnosis, and management of stress fractures in postmenopausal women. Phys Sportsmed 2012 September;40(3):3242.

(30) Russell H, Tracey J. What do injured athletes want from their health care professionals? International Journal of Athletic Therapy \& Training 2011;16(5):18-21.

(31) Saragiotto BT, Yamato TP, Lopes AD. What do recreational runners think about risk factors for running injuries? A descriptive study of their beliefs and opinions. J Orthop Sports Phys Ther 2014 October;44(10):733-738.

(32) Strauss A, Corbin J. Basics of Qualitative Research: Grounded Theory Procedures and Techniques. Thousand Oaks, CA: Sage Publications; 1990. 
(33) Taunton JE, Ryan MB, Clement DB, McKenzie DC, Lloyd-Smith DR, Zumbo BD. A prospective study of running injuries: the Vancouver Sun Run "In Training" clinics. Br J Sports Med 2003 June;37(3):239-244.

(34) Tenforde AS, Kraus E, Fredericson M. Bone Stress Injuries in Runners. Phys Med Rehabil Clin N Am 2016 February;27(1):139-149.

(35) Tenforde AS, Sayres LC, McCurdy ML, Sainani KL, Fredericson M. Identifying sexspecific risk factors for stress fractures in adolescent runners. Med Sci Sports Exerc 2013 October;45(10):1843-1851.

(36) Timpka T, Jacobsson J, Dahlstrom O et al. The psychological factor 'self-blame' predicts overuse injury among top-level Swedish track and field athletes: a 12-month cohort study. Br J Sports Med 2015 November;49(22):1472-1477.

(37) Warden SJ, Davis IS, Fredericson M. Management and prevention of bone stress injuries in long-distance runners. J Orthop Sports Phys Ther 2014 October;44(10):749-765.

(38) Winter SC, Gordon S, Brice SM, Lindsay D, Barrs S. Overuse injuries in runners of different abilities-a one-year prospective study. Res Sports Med 2019 May 30;1-17. 